\title{
Exploring Movement Learning in Physical Education Using a Threshold Approach
}

\author{
Dean Barker \\ Örebro University \\ Gunn Nyberg \\ University of Dalarna \\ Hakan Larsson \\ The Swedish School of Sport and Health Sciences (GIH)
}

\begin{abstract}
Purpose: To describe student learning when physical education teacher and students attempted to develop movement capability. Methods: The study reports on the implementation of a 10-lesson pedagogical sequence. Data were generated using observations, interviews, and student diaries with one grade 9 class (26 students aged approximately 15 years) as they developed juggling capabilities. Data were analyzed using the notion of corporeal thresholds. Results: Results show that (a) a "throw-throw-catchcatch" pattern emerged as a corporeal threshold for juggling within the sequence; (b) most learners had crossed the threshold at the outset and were able to experiment with different forms of juggling during the sequence; (c) some students crossed the threshold during the sequence. These students experienced liminal phases, characterized by frustration and an initial feeling that they were juggling in the "wrong" way; and (d) some learners became stuck, pretended to know what to do, and did not cross the threshold during the 10 lessons. Discussion/Conclusion: Three issues related to the threshold approach are discussed: student identity and group membership, the process of learning, and the emotional dimensions of movement learning. This study is concluded with reflections on the implications of the results for scholarship.
\end{abstract}

Keywords: conceptual threshold, corporeal threshold, embodied exploration, movement capability, movement knowledge

Physical education scholars have considered how teachers can facilitate the development of movement capability at length (e.g., Chow \& Atencio, 2014; Drost \& Todorovich, 2013; Dudley, Okely, Pearson, \& Cotton, 2011; Whitehead, 2001). Scholars working from a range of theoretical starting points have proposed principles, guidelines, models, and activities designed to assist teachers as they help their students to improve their motoric capacity (Barker, Aggerholm, Standal, \& Larsson, 2018; Chow et al., 2006; Light \& Wallian, 2008). Largely missing from this scholarship, however, are descriptions of what happens once such principles, guidelines, models, and activities are put into practice. We know little about the experiences of students as they learn new capabilities in the gymnasium, nor do we have a good idea of how they begin to move differently as a result of their experiences. The aim of this study is to describe student learning taking place in a physical education class when teacher and students attempt to develop movement capability. Principles related to the idea of threshold crossing (Meyer \& Land,

(C) 2020 The Authors. Published by Human Kinetics, Inc. This is an Open Access article distributed under the terms of the Creative Commons Attribution License CC BY NC 4.0, which permits unrestricted noncommercial use, distribution, and reproduction in any medium, provided the original work is properly cited, the new use includes a link to the license, and any changes are indicated. See http:// creativecommons.org/licenses/by-nc/4.0. This license does not cover any third-party material which may appear with permission in the article. For commercial use, permission should be requested from Human Kinetics, Inc., through the Copyright Clearance Center (http://www.copyright.com).

Barker is with the School of Health Sciences, Örebro University, Örebro, Sweden. Nyberg is with the Department of Sport and Health Science, University of Dalarna, Falun, Sweden. Larsson is with The Swedish School of Sport and Health Sciences (GIH), Stockholm, Sweden. Barker (dean.barker@oru.se) is corresponding author.
2003) are employed as a framework for explaining critical aspects of the data related to learning.

\section{Facilitating the Development of Movement Capability}

The capacity to move in different ways constitutes practical knowledge. Within physical education research, this practical knowledge has been referred to as physical or motor "ability" (Theodoraki \& Kampiotis, 2007), "motor skill competence" (Stodden et al., 2008), or more commonly "skill" (Avery \& Rettig, 2015; Drost \& Todorovich, 2013). For the purposes of this study, we refer to this practical knowledge broadly as movement capability and pedagogical attempts to improve people's movement capability generally as movement education. We do not use movement education in Laban's (1948) sense, but rather as a way to distinguish education that is concerned with learning to move, from physical education. For us, physical education often incorporates a greater range of outcomes relating to health, citizenship, and so forth. Both movement capability and different forms of movement education have garnered substantial interest in recent times (Barker, Bergentoft, \& Nyberg, 2017; Light \& Kentel, 2015; Renshaw, Chow, Davids, \& Hammond, 2010). In this section, we examine three general "approaches:" (a) a direct instruction approach, (b) a nonlinear pedagogical approach, and (c) an embodied explorative approach. Two preliminary comments are warranted. First, although we propose three distinct pedagogical approaches, there is overlap. Second, we identified examples of movement education research that do not fit comfortably into any of these three approaches (Aggerholm, Standal, Barker, \& Larsson, 2018; Barker et al., 2018). Space limitations mean that this work will be left undiscussed. 
A first general approach has been referred to variously as a direct instruction teaching method (Drost \& Todorovich, 2013), a "Demonstration-Explanation-Practice" model (Tinning, 2010), and simply as a "traditional" method (Chow et al., 2007; Kirk, 2010). The approach is reproduction in Mosston and Ashworth's (2002) terms as teachers should provide a demonstration of the movement pattern to be acquired. Teachers should also make key features of successful performance explicit, give time for practice, and ensure that students receive feedback while they practice (Hall, Heidorn, \& Welch, 2011; Pedersen, 2014). The approach centers on teachers' ability to discern, and help learners to eliminate, errors (Avery \& Rettig, 2015; Männistö, Cantell, Huovinen, Kooistra, \& Larkin, 2006; Overdorf \& Coker, 2013).

A small number of investigations provide a limited picture of student learning when direct instruction approaches are employed in physical education (Byra, 2000). Restricting their review to research involving controlled trials and preintervention and postintervention tests, Dudley et al. (2011) claim that direct instruction is "the most effective [strategy] to . . improve movement skills in physical education" (p. 354). Using a repeated-measures design, Pedersen (2014) concludes that even short bouts of deliberate practice can help children perform complex motor skills. These examples compare individuals' initial performances with their final performances and thus tell us about the outcome of learning. They are, however, somewhat restricted in their capacity to tell us about the process of learning.

The second approach stems from a collection of related ideas referred to as a "dynamical systems perspective" (Fischman, 2007), a "complexity theory informed" approach (Jess, Atencio, \& Thorburn, 2011; Light, 2008), and a "constraints led, nonlinear dynamical" approach (Chow \& Atencio, 2014; Renshaw, Davids, \& Savelsbergh, 2010). The central task of the teacher in this approach is to design situations in which pupils can find appropriate ways of moving. Renshaw, Chow, et al. (2010) propose that "the essence of the constraints-led perspective is to facilitate learning environments that provide controlled boundaries of exploration in dynamic settings through the provision of task constraints" (p. 125). As with the direct instruction approach, relatively few investigations have examined the practices that emerge when nonlinear pedagogies are employed to improve movement capability in physical education contexts.

Common threads of the third approach—an embodied explorative approach - are attempts to understand body and mind as one, and help learners become more sensitive to ways of moving (Light \& Kentel, 2015; Whitehead, 2013c). Whitehead (2001) for instance, regards movement capability "not as a pure bodily capacity, [but as] a holistic engagement that encompasses physical capacities embedded in perception, experience, memory, anticipation and decision making" (p. 131). Nyberg and Carlgren (2015) also describe movement capability not as two distinct cognitive and bodily processes that occur in parallel, but as a singular process.

In terms of anticipated practices, Light and Kentel (2015) claim that teachers should help pupils to reflect on kinesthetic and technical aspects of movement. Nyberg and Carlgren (2015) suggest that experiencing variation in different ways of moving will lead to a greater appreciation of movement. In this respect, there is some similarity between embodied exploration and nonlinear pedagogic approaches. However, although nonlinear pedagogues at times stress the explorative nature of movement learning, exploration tends to be in relation to a specific movement pattern (in spectrum terms, reflecting styles F and G; Mosston \& Ashworth, 2000). Learning in other words, is convergent, and exploration is about zeroing in on the "best" or most efficient technique. For us, this distinguishes the nonlinear pedagogic approach from an embodied explorative approach, which assumes that exploration is a divergent process and that increased efficiency is not the principal concern of movement education.

In a series of studies addressing physical literacy (Almond, 2013a, 2013b; Whitehead, 2013a, 2013b), Almond (2013a) further suggests that movement education "must engage all young people with challenges that will involve them and draw out their confidence and willingness to participate" (p. 67). Examinations of resulting practices are, however, relatively light on the ground. Both Dudley (2015), and Tremblay and Lloyd (2010) argue that researchers need to develop a better understanding of student learning if embodied pedagogies are to be employed successfully.

In brief, much of the research on movement capability in physical education falls into three general approaches that focus on conceptualizing practices rather than examining experiential processes of learning, and is analytic, rather than empiric. Although this work has significant potential to guide practice, it gives few insights into how movement education occurs in physical education classrooms. The current study begins to address this omission by examining what and how students learn while engaged in a learning sequence informed by an embodied exploration perspective. Importantly, pedagogical practices originating from all three approaches require critical attention. This study should, therefore, be seen as a contribution to a larger task of understanding practices of movement learning in situ. In the next section, we put forward a framework for thinking about movement learning that is consistent with embodied exploration and the idea that cognition and corporeality can be seen as "two sides to the same coin."

\section{Theoretical Framework: Movement Learning and Corporeal Thresholds}

To conceptualize the process of developing movement capability, we draw on and extend the notion of conceptual threshold crossing (Meyer \& Land, 2003). A conceptual threshold has been used to refer to an important idea within a given discipline that once grasped, opens up previously inaccessible ways of understanding (e.g., Clouder, 2005; Kiley \& Wisker, 2009; Wright \& Gilmore, 2012). In economics for instance, grasping "supply and demand" enables students to understand how economies work more generally (Meyer \& Land, 2003). Although the term has quite strong cognitive connotations, change is generally not seen in purely intellectual terms. Indeed, a number of scholars employing the notion of conceptual thresholds stress that threshold crossing has transformative consequences in that it allows, sometimes even forces, learners to take on new identities (Lucas \& Mladenovic, 2007; Meyer \& Land, 2012). An individual who understands supply and demand becomes someone who "gets" economics, who sees themselves as a capable student of economics, and who may eventually go on to identify as an "economist."

The notion of conceptual thresholds has been used in sport contexts (Barker, Barker-Ruchti, Rynne, \& Lee, 2014), but to our knowledge, has not been used as a way of considering how people learn to move. In our view, and as we will show in the second part of the article, the notion of threshold crossing has considerable explanatory value in movement education contexts. Just as certain ideas open up new ways of seeing and being in the world, certain forms of bodily knowledge can be seen as generative and transformative. Learning to balance on a moving bicycle, for example, opens up opportunities to steer the bike, to turn corners, to brake and vary speed, and ultimately to develop an identity as a "bike rider." Without the practical knowledge of being able to balance a bicycle in motion, however, possibilities to develop other 
capabilities do not present themselves. In line with a practical view of knowledge, we use the term corporeal thresholds to refer to bodily knowledge that is necessary for learners to gain entry into, and develop further capability in, particular ways of moving. In this sense, we take a "participatory" approach to learning (Sfard, 1998).

Other characteristics of threshold thinking can be applied to movement capability. Meyer and Land (2012) suggest that once a threshold has been crossed, it is very difficult to "uncross." In fact, cycling is often used as a case in point of irreversibility-one "never forgets how to ride a bike." Second, as we have suggested, thresholds are "integrative" (Meyer \& Land, 2012). Crossing thresholds offers opportunities for further understanding. Perkins (2012) refers to threshold concept epistemes, where individuals gain access to "a system of ideas or a way of understanding that allows [learners] to establish knowledge" (p. 42). Third, threshold crossing is often accompanied by a "liminal" stage (Meyer \& Land, 2003), in which old ideas and practices are inadequate but new ones remain unclear or unavailable. This stage is characterized by instability and individuals often vacillate between knowing and not knowing. Finally, although crossing thresholds may sound enlightening and positive, Perkins (1999) notes that crossing may be troublesome and difficult. New knowledge may prove disruptive and appear counterproductive to successful functioning. In this respect, learning to move differently could be accompanied by a range of emotional consequences.

\section{Methodology}

This investigation explores processes around pedagogical innovation and learning and in that respect, it is similar to Ní Chróinín, Fletcher, and O'Sullivan's (2015) work. We have drawn quite heavily on our own experiences of producing varied forms of qualitative data to examine learning in physical education contexts (Barker, Barker-Ruchti, \& Pühse, 2013; Quennerstedt et al., 2014). In the below section, we detail the pedagogical sequence that we developed to structure the environment in which movement learning took place. We then explain how we produced data within this environment to address our research aim.

\section{The Pedagogical Sequence}

To begin our empirical task, we created an embodied exploration sequence with aims and activities that could be implemented in a physical education setting. The three authors drafted a plan of 10 lessons suitable for high school students. The overall aim of the sequence was to help learners improve movement capability in relation to juggling. In line with an embodied exploration approach (Light \& Kentel, 2015; Nyberg \& Carlgren, 2015), the learners' general assignment was to develop a thorough appreciation of juggling. Juggling was selected because it falls outside a "mainstream sport" category, which has disadvantaged students without sporting backgrounds (Tidén, Redelius, \& Lundvall, 2017).

In developing our embodied explorative pedagogical approach, we worked with theories of Ryle (2009) and Polanyi (1969, 2002) that concern practical and tacit dimensions of knowing. We started from the premise that movement capability comprises physical and mental practices (Ryle, 2009; Whitehead, 2013a) and that juggling involves a transaction between subsidiary awareness, focal awareness, and mover (Polanyi, 1969, 2002). In practice, the theoretical underpinning led the teacher responsible for the class to (a) provide students with opportunities to practice without imposing a predetermined, instructional framework; (b) adopt a curious attitude toward the students' previous and current movement experiences;

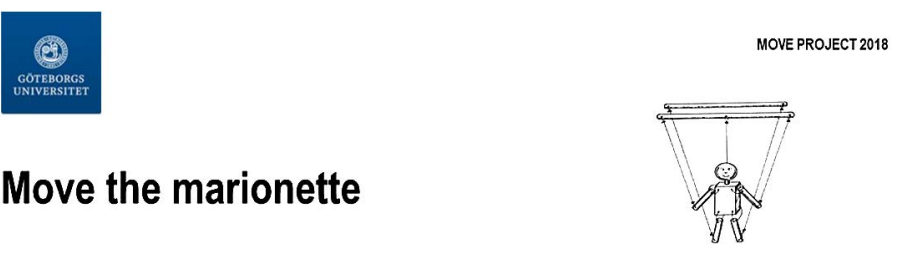

- At this station, one person will be a marionette and the other will be a puppeteer (a person who controls the marionette). There are no objects to juggle - the puppeteer should simply move the marionette in realistic juggling motions. The puppeteer can hold the marionette directly or can pretend that they are connected with invisible steel cables. Try altering the speed and height of the tosses. Maybe the marionette can even do some tricks! Make sure both partners get a chance to be marionette and puppeteer.

Figure 1 - Station card exemplar.

(c) allow students sufficient time to "dwell in" the movement; and (d) encourage students to alternate between focusing on isolated aspects of juggling and juggling as an integrated whole.

In terms of implementation, the first four lesson plans were based on station cards that the students could visit, collect inspiration and instruction from, and use to facilitate conversation and reflection. The station cards invited students to discuss different ways of juggling with one, two, and three balls, with scarves and hoops, with peers, with music, and in between practicing, reflect on what was difficult, helpful, frustrating, and so forth (see Figure 1). During these lessons, the teacher gave organizational directions to start and finish the lesson, circulated among the student groups asking contentrelated questions and providing encouragement, and attempted to keep students on task. Lessons 5-7 involved teacher- and peer-led activities. These activities were designed to give students opportunities to further dwell in juggling, discuss aspects of juggling with one another, and challenge themselves with new tasks. In these lessons, the teacher adopted a more directive role, demonstrating tasks to the students, and monitoring the students' participation. The students used the final three lessons of the unit to prepare and present a group performance for the rest of the class. In these lessons, students were invited to help one another and demonstrate their new juggling capabilities. In these final lessons, the teacher reverted to the facilitator role that he occupied in Lessons 1-4.

\section{Data Production}

In this subsection, we describe four aspects of data production: the participants, the data production procedures, the data analysis procedures, and the ethical principles adopted in the investigation.

Participants. While the pedagogical sequence was being created, seven teachers from three schools near to the university where the project was based were contacted and invited to participate. The voluntary nature of participation meant that teachers who were interested in the project and felt that the project was in line with their school's educational programs and scheduling requirements, agreed to take part. In this respect, sampling could be termed a combination of convenience and purposive (Berg, 2001). Two teachers from one of the schools agreed to participate. In the interests of analytic depth, this study reports on the results of the lessons with one of these teachers. The teacher-Jon (pseudonym) — had two and half years of teaching experience, all from the same middle- to upper-class, culturally homogenous (Swedish) school. Judging from 
our collaboration with Jon, he enjoyed experimenting with his teaching. He stated that he agreed to participate because he believed taking part would help him to improve. Jon selected one of his Grade 9 classes with which to conduct the investigation. Jon's selection was based on his assessment of the appropriateness of the content of the pedagogical sequence in relation to the topics already covered by the class, and the capacity of the students in the class to work for a sustained period with juggling. The class contained 26 students (14 girls and 12 boys) aged 15 and 16 years who, in line with the school's profile, were predominantly from middle-class, Swedish families.

Once Jon had agreed to take part, he was invited to look over the sequence plan and, in collaboration with the research team, decide which of the activities he would use and how much time he would dedicate to the activities. Jon was asked to take on a "facilitator" role during Lessons $1-4$ and 8-10 and a directive role in Lessons 5-7. In accordance with Almond's (2013a, 2013b) interpretation, we described a facilitator as someone who stimulated reflection and dialogue rather than instructed students directly, and continued to encourage the students to try moving in ways in which they were "not yet quite capable."

Data production procedures. Data were produced using three methods: (a) observations, (b) student interviews, and (c) student diaries. During the sequence, observations were carried out by the three members of the research team. Two researchers circulated in the learning environment with chest-mounted GoPro video cameras (San Mateo, CA). These two researchers filmed individual students and groups of students, remaining with individuals/groups for approximately $5 \mathrm{~min}$ at a time. As part of the observations, one researcher also took field notes during the lessons. The notes focused on topics such as participants' engagement with the tasks, moments when students appeared to make progress, and situations where students expressed emotion. Notes were both descriptive and reflective in nature and accounts of occurrences were recorded alongside impressions. Field notes were expanded in postlesson discussions with the other two researchers and in most cases, the participating teacher. The notes were then typed up by the note-taking researcher and sent to the other researchers for additional commentary.

The empirical work is most accurately described as "participant observation" (Angrosino, 2005) given that the researchers entered the lessons as "interested physical educators." In addition to the observations (filming and field notes), the two researchers filming held a number of ethnographic-type conversations (Spradley, 1979) with the students during the lessons. These conversations involved questions about motives and evaluations (e.g., Why have you chosen this task? Which way do you find easiest?) and were captured with the GoPro cameras. One of the two researchers also conducted a series of more formal interviews during the seventh and eighth lessons with nine students who appeared either very comfortable or rather uncomfortable with juggling. Again, these interviews were recorded with the researcher's GoPro camera. These interviews offered the students between 5 and $10 \mathrm{~min}$ to describe their experiences during the lessons and provide information about their movement experiences outside of physical education.

Finally, students were asked to keep learning diaries (Maivorsdotter \& Lundvall, 2009) in which they recorded their own reflections. Diaries were logged electronically using the school's learning platform. Approximately 15 min of each lesson was devoted to diary writing and students used their phones to make entries. To structure the use of the diaries and to stimulate reflection, the students were asked questions such as: "what factors helped/hindered you in your learning today?" "what did you pay particular attention to when you were practicing?" "did any problems arise when you were learning to move?" and "how do you typically solve problems during these learning sessions?" Questions were communicated either on paper instruction sheets, on the gym whiteboard, or verbally by the teacher.

Data analysis procedures. In line with the aim of the investigation, our general question of the data was, "how can the learning process be described?" This question drew attention to many aspects of the situation but in line with the notion of conceptual thresholds (Meyer \& Land, 2012), we were particularly interested in moments where students appeared to understand or grasp an aspect of juggling. After adapting the idea to our data, we set about investigating how corporeal thresholds could be used to make sense of the data and what insights it could offer.

Practically, analysis involved working with the data from each lesson in several steps. As a preliminary step, we read the field notes taken during the observation of each lesson. The field notes provided a sense of how the lesson had proceeded and in several cases contained references to "aha moments" and student improvement. We then watched the film clips of each lesson and systematically coded all filmed occurrences including the ethnographic and more formal interviews on a minute-by-minute basis. To do this, we created a table in Word that contained the column headings: time, persons in frame, and description/code with 1-min intervals. We then completed the table while watching and rewatching the clips. The result was an extensive Word document that summarized all video footage of the lessons (i.e., not just the footage involving threshold crossing). With this process completed, we went back to the film segments that had a description relating to threshold crossing to watch again. Rewatching involved multiple screenings, during which we noted aspects such as what the threshold crossing related to, who was making or describing the crossing, and in which circumstances the crossing was taking place (e.g., were others present?). After examining the video material, we turned to the students' diaries. In contrast to our handling of the film material, our coding work with the diaries focused specifically on threshold crossing. We were interested in students' comments concerning experiences of success or recognition, and the ways that "threshold crossing students" described their general experiences. These entries were highlighted, labeled, and used to develop explanations of how and why some students experienced threshold crossing.

As will be discussed in the next section, the question of why some students did not cross thresholds also surfaced during analysis. Specifically, a small number of students in the class did not manage to juggle after 10 lessons, at least not in the way they expected. With the previous analytic activities complete, we focused on the observation, interview, and diary data produced with these students and developed a theoretically grounded account of why these students did not manage to juggle in the same ways as their classmates.

Ethical principles. Ethical approval was granted by the Gothenburg Regional Research Ethical Review Committee. The research was conducted in accordance with the Swedish Research Council's ethical guidelines. Participants and their guardians were informed about the project, its purpose, and how collected material would be used. Informed, active consent was obtained from the participants. Participants had the possibility to cease participation in the project at any time. One student chose to cease participation, and her/his data do not appear in this study. The use of video cameras raises issues of confidentiality, possibilities for anonymity, and privacy for all participants. The video-filmed material was only used for research purposes and was stored in a manner that prevents 
unauthorized use. Anonymity was not possible or desirable in the analysis of the data. Instead, we aimed for anonymity in the presentation/publication of the research results. This involves using fictitious names for schools, teachers, and students, and excluding information that could be used to identify participants.

\section{Findings}

The idea of a corporeal threshold related to juggling serves to frame our description of the learning that occurred over the 10 lessons. We provide a brief explanation of the threshold, followed by a description of the group of students who had already crossed the juggling threshold when the lessons started, the group of students who crossed the threshold during the lessons, and the group who did not manage to cross the juggling threshold. In line with the aim of the study, these results provide an illustration of what can occur when movement education takes place in a physical education setting.

\section{The Throw-Throw-Catch-Catch Threshold}

Despite instructions to explore different ways of juggling rather than juggle three objects continuously and despite encouragement to develop an appreciation of aspects of juggling such as rhythm, timing, and weighting, practically all of the students identified a diagonal "throw-throw-catch-catch" pattern (see Figure 2) as the standard for knowing how to juggle. The movement pattern, accompanied by circular motions of the hands and an eye focus on the top of the implements' flight trajectory, became the corporeal threshold for the class members to cross to "become jugglers." In Irvine and Carmichael's (2009) terms, the throw-throw-catchcatch constituted an element of the class's "shared repertoire" (p. 104). It was a practice around which students negotiated identities and group membership. Students who grasped the "throw-throw-catch-catch" pattern became part of the group of "expert" jugglers within the class and could offer knowledgeable commentary to the researchers and their peers. Students who had not grasped the "throw-throw-catch-catch" pattern continued attempting to, in the words of one student, "keep three balls in the air." For observers, a typical indication that a student had crossed the threshold was that they started to make small hand rotations in preparation for tossing the balls.

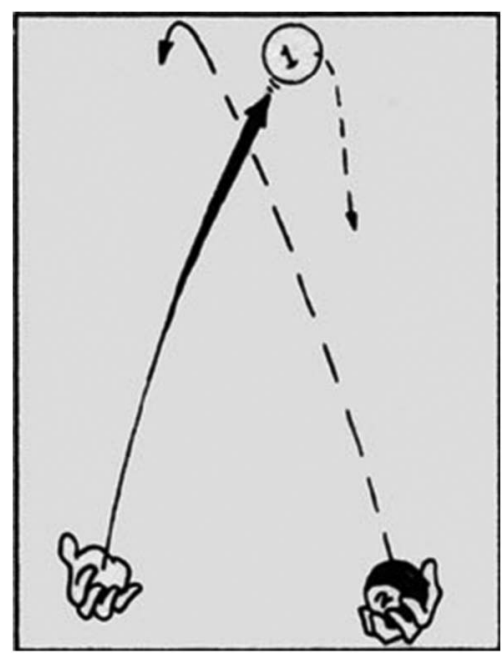

Figure 2 - Throw-throw-catch-catch pattern.

\section{Already Crossed the Threshold}

Over half of the students in the class (15/26) had already crossed the juggling threshold when the unit started. These students could perform the diagonal "throw-throw-catch-catch" pattern and could participate in most of the activities throughout the sequence. Although there were small differences, most of these students experimented with juggling in an integrative manner (Clouder, 2005), juggling with different objects and in different ways, and improved by being able to juggle for longer periods. A small group of these students were what we termed "extra engaged." These students continued to practice when they were asked to listen to instructions and on occasion practiced after the lesson had finished. At the end of Lesson 3 for example, Tina was tossing a club while her peers were writing in their diaries. Despite friendly attempts from her partner to take the club, she persisted and went on to try looping the club behind her back. Her informal practicing lasted for approximately 4 min after most of the class had left the gym. It appeared difficult for these students to communicate why they attempted to experiment, as a short extract from the field notes suggests:

I have a brief conversation with Vincent. I ask him why he keeps trying new things. He says that he likes to challenge himself . . .

Vincent: I started with the rings because I saw someone else doing it.

\section{Barker: And the basketballs?}

Vincent: I play basketball. It's harder. And I was trying with three balls but I couldn't hold them all so I thought that it would be easier to kick one up.

\section{Barker: Anything else?}

Vincent: Yeah, I want to try with the juggling clubs. It feels like I have tried everything else. (Lesson 7, Observations)

Despite having difficulties accounting for why they were experimenting, by the end of the sequence these extra engaged students could juggle with four balls, and/or juggle balls and clubs simultaneously, and/or begin by juggling volleyballs with their feet and then change to the hands, for example.

\section{Crossed the Threshold During the Teaching Sequence}

Five of the 26 students started the sequence without knowing the "throw-throw-catch-catch" pattern but crossed the threshold during lessons. These students started with two balls and juggled by doing a "handball swap"- - essentially tossing the first ball into the air, transferring the second ball quickly from the second hand to the first, and then catching the first ball in the empty hand. These five students indicated that there was something wrong or strange with their handball swap method and sought assistance from others. Eleanor for example, was comparing her swap method with two of her peers when one of us (G. Nyberg) joined her group. She showed G. Nyberg her handball swap while giggling and after a couple of attempts asked, "But how do you juggle anyway?" (Lesson 1, Observations).

The identification of something "wrong" with one's knowledge is consistent with Meyer and Land's (2012) description of how learners begin to understand troublesome concepts. Meyer and Land (2012) propose that threshold crossing often requires some form of provocation that prevents individuals from continuing with 
the same understanding or practice. For Eleanor and the other novice jugglers who crossed the threshold, the presence of peers and the failure to "keep the balls in the air" provided sufficient stimulus for change.

Change was not instantaneous and developing a sensitivity to different juggling methods occurred as a liminal phase (Meyer \& Land, 2003) where the students recognized a new way of juggling but could not enact it. This liminal phase was short for four of the five learners (juggling threshold crossed in the first or second lesson), but longer for the fifth learner (threshold crossed in Lesson 9). The phase involved unsuccessful attempts to cast all three balls into the air simultaneously and resulted in increased failures before the students began to demonstrate the throw-throw-catch-catch pattern.

The four students who crossed early in the sequence assumed a persistent attitude to juggling, characterized by moderate frustration and continual attempts. Near the start of the second lesson, Lina dropped her balls repeatedly. Her puff as she picked them up occurred just as G. Nyberg approached (Observation):

G. Nyberg: Lina, are you getting a bit angry now?

Lina: Yes, I'm getting angry now. (laughs)

G. Nyberg: Why? (laughs)

Lina: Because it's not working! (laughs)

G. Nyberg: What's not working?

Lina: Juggling!

G. Nyberg: Yes, but ...

Lina: The balls are flying away!

Several scholars have noted relationships between emotions and identity (e.g., Clouder, 2005). Lucas and Mladenovic (2007) suggest that emotions such as anger and resentment may signal a "threshold concept in the vicinity" (p. 5). They claim that such negative emotions tend to precede threshold crossing and rather than barriers to learning, should be seen as signs of imminent threshold crossing. This contention is partly supported by our observations and we would add that students who did not cross the corporeal threshold also expressed frustration at times.

Finally, this group of students started to describe juggling with different terms. Instead of talking about "keeping three or more objects in the air" (Harry, Lesson 3, student who eventually crossed threshold in Lesson 9), they began to refer to rhythm and patterns. This change in talk is in line with threshold research that suggests that changes in learners' ways of talking reflect changes in sense making (Meyer \& Land, 2003). From a pedagogical perspective, this means that listening carefully to ways that learners describe lesson content and difficulties could be a way to facilitate learning, an idea we return to in the final section of the article.

\section{Did Not Cross the Threshold During the Sequence}

Six students in the class had not crossed the threshold when they started and did not cross the threshold during the sequence. In line with the teacher's grouping strategy, these students were spread among the other students in the gym. They were difficult to identify without the assistance of the video footage because they engaged in ways similar to their peers. In Lesson 7, for example, when many students were experimenting with creative forms of juggling, Johan was attempting to juggle beanbags behind his back, despite claiming that he had not grasped the throw-throw-catch-catch pattern. This kind of mimicry is not uncommon among learners who are "stuck" (Kiley \& Wisker, 2009), and Kiley (2009) suggests that learners who find themselves unable to cross thresholds often pretend to know what is required by "copying the language, behavior, and presentation of the perceived desirable understanding" (p. 294). At different points during our sequence, these students spent considerable time watching others juggle, searching for equipment with which to practice, or talking to practicing peers.

The "stuck" phase can be risky for learners in two ways. First, learners can lose confidence and question their contextualized identities (Kiley \& Wisker, 2009), in this case as capable movement learners. Second, the activity can either lose, or fail to acquire, meaning for the learner (Meyer \& Land, 2003). In either case, the likelihood of the learner crossing the threshold decreases rather than increases over time, making crossing a matter of relative urgency. A short interview from Lesson 7 illustrates a waning interest in juggling:

H. Larsson: Have you discovered something that you think, I need to be able to get this?

Johan: What I forget is, that when I've caught the ball, I need to throw it again.

H. Larsson: I think I understand. You mean that you find yourself standing with the balls in your hands?

Johan: Mm. When I've caught it I forget that I am supposed to throw it again ...

H. Larsson: Oh, ok. Have you asked (teacher) what the next step might be? Or a friend?

Johan: Mm . . . no.

H. Larsson: Has someone said something? Maybe try it like this?

Johan: No.

As well as being stuck, these nonthreshold crossing students at times appeared isolated in group work situations (i.e., much of the sequence), as field notes from observations of Lesson 8 illustrate:

Linn, Anna and Hilde's group. Neither Linn nor Anna can juggle with three balls but they are trying. Anna does not have the rhythm and tries to throw two balls simultaneously with her third toss ... The other two girls in the group are "inward-oriented" and are not paying attention to Anna, let alone thinking about how they could help her. Group work is not working here.

On occasions when these students did participate in their groups' conversations, it tended to be as the "ones who could not juggle yet" or the "ones who needed help" (Lesson 7, Observation). These students did not seem to benefit from the instructional/ inspirational material or the assistance from their peers or teacher.

Somewhat unsurprisingly, these students expressed disappointment during the sequence. Åsa, for example, wrote as follows:

Own reflection-I'm getting really frustrated about not being able to juggle because I look around the room and see all those people who can juggle and I know that I want to be able to too and when I don't get it, I get angry at myself for not getting it. But on the other hand, I would have been frustrated if I was alone and failed. I know that you have to fail about 100 or 1000 times before you succeed but when the exercises are getting 
harder and you feel that you're not really getting anywhere, it becomes difficult not to be disappointed / angry with yourself. (Lesson 3, Diary)

Åsa's entry is typical of the students who did not grasp the throw-throw-catch-catch pattern, particularly her claim that "everyone else can juggle." They tended to withdraw from peers who had crossed the threshold and their participation was characterized by either individual "practicing" or help seeking.

Like frustration, emotions such as sadness and despondency can also be related to learners' identities. Unlike frustration, sadness is more likely to be related to learners' inability to leave behind old understandings (Lucas \& Mladenovic, 2007) and prevent threshold crossing. Although it is difficult to say precisely what these students were unable to leave behind, our impression is that they had trouble relinquishing the idea that juggling was difficult and accepting that juggling with three balls is a simple activity. Regardless of cause, however, sadness and despondency appeared to be learning retardants.

\section{Concluding Thoughts}

The aim of this study was to describe student learning taking place in a physical education class when teacher and students attempted to develop movement capability. In addressing this aim, we have demonstrated the utility of a threshold approach. We have shown that movement activities such as juggling can be seen to contain corporeal thresholds, which are necessary for learners to cross if further capabilities are to be developed. We have suggested that learners' participation in classes is significantly shaped by their relations to these thresholds. Furthermore, we have highlighted some of the affective elements of corporeal threshold crossing.

We would like to finish by returning to some of the issues raised in the previous section, and in the process, present reflections on implications for future research. The first concerns the ways learners talk and act. The threshold framework suggests that careful listening and observation can provide teachers with insights into learners' development of movement capability. Particular descriptive terms and preparatory movements for example, signal learners' unique approaches to ways of moving. Learners' approaches can in turn, help or hinder their attempts to cross (corporeal) thresholds. The idea of sensitive listening/observing aligns with Almond's (2013b) call for an empathetic pedagogy that accounts for how learners make sense in and of moving (Light \& Kentel, 2015; Whitehead, 2013b). This subjective dimension of learning has been largely omitted from investigations of direct instruction (e.g., Avery \& Rettig, 2015; Männistö et al., 2006; Overdorf \& Coker, 2013) and to some extent nonlinear dynamical pedagogies (e.g., Chow \& Atencio, 2014; Renshaw, Chow, et al., 2010), which place more emphasis on learning environment and movement outcomes. We believe it would be generative to examine and compare learners' ways of talking and moving while they practice and receive feedback (Hall et al., 2011; Pedersen, 2014) and/or participate in environments designed to facilitate the emergence of new ways of moving (Jess et al., 2011; Light, 2008). From our experience in this study, our sense is that teachers working with movement education tacitly appreciate students' ways of talking/ moving and recognize how at least some of these ways relate to the development of movement capability. At the same time, further research into both students' and teachers' talk/actions during movement education could provide increased transparency and clarity, and have significant relevance for physical education teacher education.

Second, further attention to the affective dimensions of movement development appears necessary. Our examination based on the idea of threshold crossing points to the importance of aspects such as frustration and despondency in the development of movement capability yet only a handful of physical education scholars have broached these aspects as pedagogically and analytically relevant (Almond, 2013a, 2013b; Whitehead, 2013a, 2013b). Again, this oversight appears to be related to how movement capability and movement education are conceived. If movement capability is understood as a physical skill (e.g., Avery \& Rettig, 2015; Drost \& Todorovich, 2013), a consideration of emotions is unnecessary, or at least optional. If movement capability is understood nondualistically (Almond, 2013a, 2013b; Whitehead, 2001), the emotional cannot be sequestered from the physical or intellectual, and must be accounted for.

Finally, following calls for a better understanding of student learning in movement contexts (Dudley, 2015; Tremblay \& Lloyd, 2010), we have through the use of threshold thinking, demonstrated how students in one physical education class engage in movement education in one of three ways: (a) capable movers who can use existing knowledge to experiment with new ways of moving in an integrative manner; (b) developing movers involved in a liminal process where their attempts to move in new ways are accompanied by frustration and brief moments of success; or (c) "stuck movers" who mimic the actions of others, are at risk of becoming isolated and despondent, and are unlikely to cross corporeal thresholds. This complexity has obvious implications for practice and educators may recognize similar forms of participation. In terms of research, however, diverse forms of participation encourage scholars-regardless of whether they are interested in direct instruction, nonlinear pedagogy, or embodied explorationto place more emphasis on how learners engage with movement education. Greater awareness of this engagement will help scholars to refine principles, guidelines, models and activities, and assist movement educators in helping individuals move in new ways.

\section{References}

Aggerholm, K., Standal, O., Barker, D., \& Larsson, H. (2018). On practising in physical education: Outline for a pedagogical model. Physical Education and Sport Pedagogy, 23, 197-208. doi:10.1080/ 17408989.2017.1372408

Almond, L. (2013a). Physical literacy and fundamental movement skills: An introductory critique. Journal of Sport Science and Physical Education, 65, 81-89.

Almond, L. (2013b). Translating physical literacy into practical steps: The role of pedagogy. Journal of Sport Science and Physical Education, $65,64-72$.

Angrosino, M.V. (2005). Recontextualizing observation: Ethnography, pedagogy, and the prospects for a progressive political agenda. In N. Denzin \& Y. Lincoln (Eds.), Sage handbook of qualitative research (pp. 729-745). Thousand Oaks, CA: Sage.

Avery, M., \& Rettig, B. (2015). Teaching the middle school gradelevel outcomes with standards-based instruction. Journal of Physical Education, Recreation and Dance, 86(7), 17-22. doi:10.1080/ 07303084.2015 .1064697

Barker, D., Aggerholm, K., Standal, O., \& Larsson, H. (2018). Developing the practising model in Physical Education: An expository outline focusing on movement capability. Physical Education and Sport Pedagogy, 23, 209-221. doi:10.1080/17408989.2017.1371685 
Barker, D., Barker-Ruchti, N., \& Pühse, U. (2013). Constructive readings of interactive episodes: Examining ethics in physical education from a social constructionist perspective. Sport, Education and Society, 18, 511-526. doi:10.1080/13573322.2011.601290

Barker, D., Barker-Ruchti, N., Rynne, S., \& Lee, J. (2014). "Just do a little more:" Examining expertise in high performance sport from a sociocultural learning perspective. Reflective Practice, 15, 92-105. doi:10.1080/14623943.2013.868797

Barker, D., Bergentoft, H., \& Nyberg, G. (2017). What would physical educators know about movement education? A review of literature, 2006-2016. Quest, 69, 419-435. doi:10.1080/00336297.2016.1268180

Berg, B. (2001). Qualitative research methods for the social sciences (4th ed.). Boston, MA: Allyn \& Bacon.

Byra, M. (2000). A review of Spectrum research: The contributions of two eras. Quest, 52, 229-245. doi:10.1080/00336297.2000.10491712

Chow, J.Y., \& Atencio, M. (2014). Complex and nonlinear pedagogy and the implications for physical education. Sport, Education and Society, 19, 1034-1054. doi:10.1080/13573322.2012.728528

Chow, J.Y., Davids, K., Button, C., Shuttleworth, R., Renshaw, I., \& Araujo, D. (2006). Nonlinear pedagogy: A constraints-led framework for understanding emergence of game play and movement skills. Nonlinear Dynamics, Psychology, and Life Sciences, 10(1), 71-103.

Chow, J.Y., Davids, K.W., Button, C., Shuttleworth, R., Renshaw, I., \& Araújo, D. (2007). The role of nonlinear pedagogy in physical education. Review of Educational Research, 77, 251-278. doi:10. $3102 / 003465430305615$

Clouder, L. (2005). Caring as a "threshold concept:" Transforming students in higher education into health(care) professionals. Teaching in Higher Education, 10, 505-517. doi:10.1080/13562510500239141

Drost, D.K., \& Todorovich, J.R. (2013). Enhancing cognitive understanding to improve fundamental movement skills. Journal of Physical Education, Recreation and Dance, 84(4), 54-59. doi:10.1080/ 07303084.2013 .773838

Dudley, D. (2015). A conceptual model of observed physical literacy. The Physical Educator, 72, 236-260.

Dudley, D., Okely, A., Pearson, P., \& Cotton, W. (2011). A systematic review of the effectiveness of physical education and school sport interventions targeting physical activity, movement skills and enjoyment of physical activity. European Physical Education Review, 17(3), 353-378. doi:10.1177/1356336X11416734

Fischman, M.G. (2007). Motor learning and control foundations of kinesiology: Defining the academic core. Quest, 59, 67-76. doi:10. 1080/00336297.2007.10483537

Hall, T.J., Heidorn, B., \& Welch, M. (2011). A description of preservice teachers' task presentation skills. The Physical Educator, 68, $188-198$.

Irvine, N., \& Carmichael, P. (2009). Threshold concepts: A point of focus for practitioner research. Active Learning in Higher Education, 10, 103-119. doi:10.1177/1469787409104785

Jess, M., Atencio, M., \& Thorburn, M. (2011). Complexity theory: Supporting curriculum and pedagogy developments in Scottish physical education. Sport, Education and Society, 16, 179-199. doi:10. 1080/13573322.2011.540424

Kiley, M. (2009). Identifying threshold concepts and proposing strategies to support doctoral candidates. Innovations in Education and Teaching International, 46, 293-304. doi:10.1080/14703290903069001

Kiley, M., \& Wisker, G. (2009). Threshold concepts in research education and evidence of threshold crossing. Higher Education Research and Development, 28, 431-441. doi:10.1080/07294360903067930

Kirk, D. (2010). Physical education futures. London, UK: Routledge.

Laban, R. (1948). Modern educational dance. London, UK: Macdonald \& Evans.
Light, R. (2008). Complex learning theory-Its epistemology and its assumptions about learning: Implications for physical education. Journal of Teaching in Physical Education, 27(1), 21-37. doi:10. $1123 /$ jtpe.27.1.21

Light, R., \& Kentel, J.A. (2015). Mushin: Learning in technique-intensive sports as a process of uniting mind and body through complex learning theory. Physical Education and Sport Pedagogy, 20, 381-396. doi:10.1080/17408989.2013.868873

Light, R., \& Wallian, N. (2008). A constructivist-informed approach to teaching swimming. Quest, 60, 387-404. doi:10.1080/00336297. 2008.10483588

Lucas, U., \& Mladenovic, R. (2007). The potential of threshold concepts: An emerging framework for educational research and practice. London Review of Education, 5, 237-248. doi:10.1080/14748460701661294

Maivorsdotter, N., \& Lundvall, S. (2009). Aesthetic experience as an aspect of embodied learning: Stories from physical education student teachers. Sport, Education and Society, 14, 265-279. doi:10.1080/ 13573320903037622

Männistö, J., Cantell, M., Huovinen, T., Kooistra, L., \& Larkin, D. (2006). A school-based movement programme for children with motor learning difficulty. European Physical Education Review, 12, 273-287. doi: $10.1177 / 1356336$ X06069274

Meyer, J., \& Land, R. (2003). Threshold concepts and troublesome knowledge: Linkages to ways of thinking and practising within the disciplines. In C. Rust (Ed.), Improving student learning theory and practice - Ten years on (pp. 412-424). Edinburgh, Scotland: University of Edinburgh.

Meyer, J., \& Land, R. (2012). Overcoming barriers to student understanding: Threshold concepts and troublesome knowledge. London, UK: Routledge.

Mosston, M., \& Ashworth, S. (2002). Teaching physical education. San Francisco, CA: Benjamin Cummings.

Ní Chróinín, D., Fletcher, T., \& O’Sullivan, M. (2015). Using self-study to explore the processes of pedagogical innovation in physical education teacher education. Asia-Pacific Journal of Health, Sport and Physical Education, 6, 273-286. doi:10.1080/18377122.2015.1092724

Nyberg, G., \& Carlgren, I.M. (2015). Exploring capability to movesomatic grasping of house-hopping. Physical Education and Sport Pedagogy, 20, 612-628. doi:10.1080/17408989.2014.882893

Overdorf, V., \& Coker, C. (2013). Efficacy of movement analysis and intervention skills. The Physical Educator, 70, 195-205.

Pedersen, S. (2014). Deliberate laterality practice facilitates sensory-motor processing in developing children. Physical Education and Sport Pedagogy, 19, 136-148. doi:10.1080/17408989.2012.726983

Perkins, D. (1999). The many faces of constructivism. Educational Leadership, 57, 6-11.

Perkins, D. (2012). Constructivism and troublesome knowledge. In J.H. Meyer \& R. Land (Eds.), Overcoming barriers to student understanding: Threshold concepts and troublesome knowledge (pp. 33-47). London, UK: Routledge.

Polanyi, M. (1969). Knowing and being. Essays by Michael Polanyi. Chicago, IL: University of Chicago Press.

Polanyi, M. (2002). Personal knowledge: Towards a post-critical philosophy. London, UK: Routledge.

Quennerstedt, M., Annerstedt, C., Barker, D., Karlefors, I., Larsson, H., Redelius, K., \& Öhman, M. (2014). What did they learn in school today? A method of approach for exploring aspects of learning in physical education. European Physical Education Review, 20, 282 302. doi:10.1177/1356336X14524864

Renshaw, I., Chow, Y., Davids, K.W., \& Hammond, J. (2010). A constraints-led perspective to understanding skill acquisition and game play: A basis for integration of motor learning theory and 
physical education praxis? Physical Education and Sport Pedagogy, 15, 117-137. doi:10.1080/17408980902791586

Renshaw, I., Davids, K.W., \& Savelsbergh, G. (2010). Motor learning in practice: A constraints-led approach. London, UK: Routledge.

Ryle, G. (2009). The concept of mind. New York, NY: Routledge.

Sfard, A. (1998). On two metaphors for learning and the dangers of choosing just one. Educational Researcher, 27, 4-13. doi:10.3102/ 0013189X027002004

Spradley, J.P. (1979). The ethnographic interview. New York, NY: Holt, Rinehart \& Winston.

Stodden, D.F., Goodway, J.D., Langendorfer, S.J., Roberton, M.A., Rudisill, M.E., Garcia, C., \& Garcia, L.E. (2008). A developmental perspective on the role of motor skill competence in physical activity: An emergent relationship. Quest, 60, 290-306. doi:10.1080/ 00336297.2008.10483582

Theodoraki, K., \& Kampiotis, S. (2007). The development of movement synthesis ability through the teaching of creative movement and improvisation. Science Education International, 18, 267-275.

Tidén, A., Redelius, K., \& Lundvall, S. (2017). The social construction of ability in movement assessment tools. Sport, Education and Society, 22, 697-709. doi:10.1080/13573322.2015.1071249
Tinning, R. (2010). Pedagogy and human movement: Theory, practice, research. London, UK: Routledge.

Tremblay, M., \& Lloyd, M. (2010). Physical literacy measurement: The missing piece. Physical and Health Education Journal, 76(1), 26-30.

Whitehead, M. (2001). The concept of physical literacy. European Journal of Physical Education, 6(2), 127-138. doi:10.1080/1740898010060205

Whitehead, M. (2013a). Content implications of working to promote physical literacy. Journal of Sport Science and Physical Education, 65, 90-97.

Whitehead, M. (2013b). Creating learning experiences to foster physical literacy. Journal of Sport Science and Physical Education, 65, 73-80.

Whitehead, M. (2013c). What is physical literacy and how does it impact on physical education? In S. Capel \& M. Whitehead (Eds.), Debates in physical education (pp. 37-52). London, UK: Routledge.

Wright, A.L., \& Gilmore, A. (2012). Threshold concepts and conceptions: Student learning in introductory management courses. Journal of Management Education, 36, 614-635. doi:10.1177/ 1052562911429446 